\title{
OCHRONA ZABYTKÓW ARCHEOLOGICZNYCH W PRAWIE JAPOŃSKIM
}

\section{Wprowadzenie}

Społeczeństwo Japonii jest zorganizowane hierarchicznie. Wiele osób słyszało o tradycyjnym japońskim powitaniu, jest ono bardzo formalne i zrytualizowane. Polega na złożeniu pokłonu drugiej osobie. Poprzez składany pokłon osoba witająca się okazuje szacunek, adekwatny do wieku i statusu osoby witanej. Im starszy wiek lub wyższy status społeczny, tym niższy pokłon. Japończycy, czy to w sytuacjach codziennych spotkań, czy podczas spotkań biznesowych są bardzo świadomi swojego wieku i statusu. Jednocześnie są także świadomi swojej kultury, pochodzenia i dziedzictwa narodowego, na którego ochronie bardzo im zależy.

Rząd Japonii zachęca do powszechnego udziału społeczeństwa w popieraniu i docenianiu działań artystycznych. Już na poziomie liceum istnieją szkoły publiczne i prywatne kładące nacisk na kształcenie artystyczne, a także wiele szkół artystycznych i akademii, w których uczniowie moga przygotowywać się do kariery zawodowej artystów. Ministerstwo Edukacji udziela oficjalnego wsparcia i mecenatu nad większością działań związanych ze sztuka, w tym z edukacją artystyczną w szkołach i muzeach, bibliotekach i innych instytucjach. Ministerstwo ogólnie przyjmuje konserwatywne stanowisko, które faworyzuje tradycyjną sztukę i rzemiosło oraz „kulturę wysoką"1.

Ciekawym aspektem japońskiej polityki artystycznej jest zdefiniowanie i określenie kryteriów klasyfikacji „skarbów narodowych”. Skarbem narodowym są ważne dobra kultury, które cechuje ich szczególnie wysoka wartość dla światowej historii kultury lub narodu japońskiego. Moga nimi być zarówno wspaniałe dzieła sztuki: obrazy, rzeźby lub arcydzieła architektury, jak i formy sztuki (np. sztuka artystycznego eksponowania kamieni, ceremonia parzenia herbaty czy sposób układania kwiatów), a nawet sami artyści. Na przykład wiele rzemiosł ludowych zostało określonych jako ,niematerialne dobra kultury”, a zdarza się też, że sami artyści - znany garncarz, tkacz lub rzeźbiarz - są określani jako „żywy skarb narodowy”. Wiele

\footnotetext{
ORCID: 0000-0002-4708-2504, DOI: 10.4467/23538724GS.21.010.14842

1 T.C. Bestor, Countries and their cultures, https://www.everyculture.com/Ja-Ma/Japan.html (dostęp: 19.02.2021).
} 
tradycyjnych form artystycznych i gatunków estetycznych jest uznawanych za typowo japońskie, np. drzeworyty ukiyo-e, formy dramatyczne, takie jak Nōi Kabuki, ogrodnictwo krajobrazowe, style architektoniczne, gatunki poetyckie, takie jak haiku, filozofia zen, kompozycje kwiatowe (ikebana), ceremonia parzenia herbaty i muzyka bębnów taiko ${ }^{2}$.

Japończycy wyjątkowo cenią sobie swoja historię. Wspominaja i uwieczniaja ją w sztuce, a odkrywając stanowiska archeologiczne czy zabytki, zabezpieczaja je i chronią. Japońskie prawo ochrony zabytków, choć wprowadzone dopiero po dramatycznej utracie części dziedzictwa, było już głęboko zakorzenione w myśleniu Japończyków. Było też od wieków, bez odgórnego nakazu częściowo stosowane. Celem artykułu jest przybliżenie prawa, które w długiej historii narodu japońskiego chroniło i wspierało wyspę pełną ciekawych stanowisk archeologicznych. Przez ponad tysiąc lat świątynie i ogrody Hiraizumi zachowały swoje oryginalne cechy. Mimo że ich drewniane konstrukcje były celowo wielokrotnie niszczone, jak również ulegały naturalnemu zużyciu, to właśnie dzięki zaangażowaniu lokalnego społeczeństwa i silnemu poczuciu własnego dziedzictwa możemy wciąż podziwiać to miejsce. Także krag kamienny Omori Katsuyama nie został zniszczony przez rolników ani rozkradziony przez okoliczną ludność ze względu na ich przywiązanie do symbolicznego znaczenia tego miejsca.

\section{Krótka historia zasiedlenia Japonii}

Japonia jest jednym z najbardziej zaawansowanych technologicznie krajów świata. Jest położona w archipelagu Azji Wschodniej, na który składają się cztery główne wyspy i ponad 6800 innych pomniejszych. Większość terytorium Japonii jest pokryta górami i gęsto zalesionymi obszarami. To kraj z trzecim największym systemem gospodarczym ${ }^{3}$. Można prześledzić zjednoczenie i rozkwit Japonii od końca IV w. p.n.e. Cywilizacja japońska kształtowała się od końca VIII do końca XII w. Choć dzisiaj kojarzymy Japonię głównie jako kraj kwitnącej wiśni, samurajów, gejsz, pól ryżowych i pysznej zupy ramen, to każdy z tych elementów jest względnie nowy. Przywołane tu tradycje maja bowiem zaledwie kilkusetletnią tradycję, podczas gdy sama historia Japonii zaczęła się nawet nie wieki, lecz tysiąclecia wcześniej.

Nikt nie jest do końca pewien, kiedy pierwsi ludzie pojawili się w Japonii. Niektórzy twierdzą, że już 500 tys. lat temu ${ }^{4}$ a są i tacy, którzy spodziewają się, że w niedłu-

2 A.G. Grapard, Nature and Culture in Japan, „Kyoto Journal”, 30.11.2012, https://kyotojournal.org/culture-arts/nature-and-culture-in-japan/ (dostęp: 19.02.2021).

3 Japan - Country Profile, Facts, News and Original Articles, Global Sherpa, http://globalsherpa. org/japan/ (dostęp: 10.01.2020).

4 K. Katayama, The Japanese as an Asia-Pacific Population [w:] Multicultural Japan: Paleolithic to Postmodern, eds. D. Denoon, M. Hudson, G. McCormack, T. Morris-Suzuki, New York 1996, s. 19. 
gim czasie zostanie udowodniona obecność człowieka na tym obszarze już milion lat temu ${ }^{5}$. Obecnie przyjmuje się, że ok. 200 tys. lat temu ${ }^{6}$ pojawili się na wyspie pierwsi ludzie (chociaż najwcześniej datowane szczątki ludzkie mają zaledwie 30 tys. lat). Do końca ostatniego zlodowacenia ${ }^{7}$, które ustało ok. 15 tys. lat temu, Japonia była połączona z kontynentem azjatyckim przez szereg mostów lądowych. Wiodły one przez Sachalin na północy, Cuszimę na zachodzie i Wyspy Ryukyu na południu. Zatem nietrudno było tu dotrzeć. Imigranci przybywali falami, zwłaszcza ze wschodu i Azji Południowo-Wschodniej już 30 tys. lat temu, a następnie dołączali do nich osadnicy z Azji Północno-Wschodniej (ok. 14 tys. lat temu) ${ }^{8}$.

Trudno jest z pewnościa przedstawić obraz życia ludzi z paleolitu (zwanego starą epoką kamienia), ponieważ zmieniła się jedna z części linii brzegowej, mosty łączące część morską z kontynentem oraz większa część lądu są teraz głęboko pod wodą. Nadmorskie miejsca, które kiedyś były zasiedlone, zostały utracone na zawsze. Z badań wynika, że mogło być znacznie więcej przybrzeżnej aktywności, niż sugeruja to ocalałe stanowiska śródlądowe. Obraz, który się wyłania z tamtego okresu, to zasadniczo małe i sezonowo ruchome grupy łowców-zbieraczy (czyli grupy skupione głównie na poszukiwaniu pokarmu w okolicy, zbieraniu mięsa już padłego lub upolowanego przez inne drapieżniki, a następnie polowaniu samemu przy użyciu prostych technik łowieckich). Myśliwi polowali nie tylko na dziki i jelenie, ale także grubą zwierzynę, taką jak słonie i żubry, chociaż te w ostatniej fazie paleolitu występowały coraz rzadziej ze względu na ocieplenie klimatu i nasilenie polowań przez rosnącą populację. Zbieracze szukali różnych jagód i orzechów. Grupy paleolityczne składały się z niewielkiej liczby rozbudowanych rodzin, liczących łącznie od 20 do 150 osób. Rozszerzone rodziny były ważne dla wychowywania dzieci, ponieważ wielu rodziców umierało przed ukończeniem 30. roku życia, a wiele osieroconych dzieci potrzebowało ochrony osób dłużej żyjących wśród dorosłych' ${ }^{9}$ Mimo że populacja rosła, prawdopodobnie nigdy nie przekroczyła 20 tys. osobników.

Pod koniec paleolitu nastąił ograniczony, ale stabilny rozwój społeczności. W ciągu kolejnych tysięcy lat doszło do wyspecjalizowania się człowieka w umiejętnościach wytwórczych, co doprowadziło do szybkiego rozwoju handlu. Już 20 tys. lat temu obsydian (wulkaniczne szkło, z którego wytwarzano narzędzia) był sprzedawany co

5 M. Okamura, A. Babadan, R. Pearson, Ancient Japan, contribution to Pearson, New York 1992, s. $49-50$.

6 R. Pearson, Ancient Japan, New York 1992, s. 38.

7 W historii Ziemi kilkakrotnie dochodziło do zlodowaceń, zwanych często epokami lodowcowymi. Momenty, w których lód zajmuje większe obszary powierzchni Ziemi, nazywa się glacjałami, zaś te, w których lądolód się cofa, ale wciąż nie zanika, nazywa się interglacjałami. Z kończącym się holocenem (epoką trwającą teraz) nadejdzie kolejna epoka zlodowacenia.

8 R. Pearson, Ancient Japan..., s. 64.

9 G. Bowles, Japanese People, Origin of, KEJ 1983, vol. 4, s. 34; W. Farris, Population, Disease, and Land in Early Japan, 645-900, Cambridge, MA 1985, s. 43. 
najmniej w odległości $150 \mathrm{~km}$ od miejsca pobytu wytwórcy. Handel prawie na pewno odbywał się drogą wodna, co wskazuje, że jednostka pływająca (tratwa lub łódka) była w użyciu od bardzo dawna.

Ludzie z epoki kamienia sa powszechnie przedstawiani jako mieszkańcy jaskiń. W przypadku Japonii jaskinie wydają się jednak rzadko wykorzystywane jako miejsca o znacznej trwałości, choć wiele z nich służyło jako tymczasowe schronienie. Preferowanie przez ówczesnych mieszkańców terenów otwartych sugeruje powszechne stosowanie sztucznych schronień, chociaż natura takiego zachowania nie jest jasna.

\section{Archeologia japońska}

Archeologię japońską definiuje się jako archeologiczne badanie dawnych kultur na obecnych Wyspach Japońskich. W rzeczywistości większość japońskich archeologów bada archeologię swojego kraju, tylko niewielki procent z ponad 5500 japońskich archeologów wykonuje jakakolwiek lub całość swojej pracy za granica, interesujacc się innymi kulturami. Archeolodzy japońscy z uwagi na bogatą historię Japonii mają wiele pracy i wiele stanowisk do odkrycia. W Kraju Kwitnącej Wiśni zabytki nigdy nie były przez mieszkańców specjalnie niszczone. Do zniszczeń dochodziło głównie w wyniku działań wojennych. Pomimo braku poczucia wspólnej tożsamości narodowej przez mieszkańców poszczególnych prefektur wszyscy dbaja o zabytki znajdujące się w ich otoczeniu.

W Japonii jest od ok. 370 tys. do 440 tys. zarejestrowanych stanowisk archeologicznych, czyli co najmniej jedno stanowisko występuje na $1 \mathrm{~km}^{2}$ kraju. Prawie $70 \%$ obszaru Japonii to strome góry, zatem zagęszczenie stanowisk archeologicznych na pozostałych 30\% powierzchni użytkowej jest niezwykle wysokie. Wstępnie szacuje się, że kilka z tych miejsc ma 50 tys. lat, ale większość ma mniej niż 35 tys. lat. Zarejestrowane stanowiska obejmują w większości stanowiska datowane na XIX w. Obecnie wielu archeologów rutynowo prowadzi wykopaliska i rejestruje stanowiska z połowy $\mathrm{XX}$ w. ${ }^{10}$ Uwaga japońskich archeologów została w głównej mierze skierowana przez społeczeństwo na popularne tematy, takie jak historia samurajów czy bitwy japońsko-amerykańskie i inne. Początki Japonii jako kraju i historia człowieka na tych terenach przez długi czas były zaniedbywane przez naukowców i pozostawione same sobie.

Wszędzie tam, gdzie żyją ludzie, ich działalność wywiera silny wpływ na kształt i historię terenu. Realizacja projektów rozwojowych, takich jak budowa autostrad czy budynków mieszkalnych, ma negatywny wpływ na stanowiska archeologiczne i wymaga badań archeologicznych prowadzonych na miejscu poprzez wcześniej przeprowadzone wykopaliska ratunkowe. Liczba wykopalisk ratunkowych w Japonii wzrosła

10 C.T. Keally, Japanese Archeology, http://www.t-net.ne.jp/ keally/jpnarch.html (dostęp: 20.02. 2021). 
wykładniczo od lat 20. do połowy XX w., odzwierciedlając szybki rozwój gospodarki narodowej w tym okresie. Od połowy XX w. nastapił stopniowy spadek liczby badań archeologicznych. W roku 2006 stworzono ok. 3 tys. projektów prac rozwojowych i budowlanych przeznaczonych do realizacji na terenach obejmujących zarejestrowane stanowiska archeologiczne. Efektem tych projektów było przeprowadzenie, po wstępnych ocenach terenu, ponad 900 ratowniczych wykopalisk. Obecnie wykopaliska ratunkowe stanowią ok. 95\% wszystkich wykopalisk archeologicznych w Japonii ${ }^{11}$.

\section{Dziedzictwo archeologiczne Japonii}

Z historycznego punktu widzenia zarządzanie dziedzictwem archeologicznym (AHM - Archeological heritage management) w Japonii rozpoczęło się dopiero w II połowie XIX w., kiedy to ustanowiono kilka przepisów krajowych, mających na celu ochronę dziedzictwa kultury, w tym dziedzictwa archeologicznego ${ }^{12}$.

Zniszczenie przez ogień malowideł ściennych w holu głównym Kondô ze świątyni Hôryû-ji w 1949 r. dało impuls do uchwalenia ustawy o ochronie dóbr kultury, czyli pierwszych w Japonii kompleksowych ram prawnych regulujących to zagadnienie. Nowy akt prawny zastapił dotychczas obowiązujące ustawę o ochronie dóbr narodowych, ustawę o konserwacji ważnych dzieł sztuki oraz prawo dotyczące zachowania historycznych miejsc, malowniczych miejsc i pomników przyrody, poszerzając i wzmacniając istniejący system ochrony. Wraz ze wzrostem świadomości społeczeństwa w kontekście potrzeby ochrony dziedzictwa kultury do tych aktów prawnych w kolejnych latach wprowadzano poprawki ${ }^{13}$.

Obecny krajowy system AHM, którego głównym składnikiem jest ratownicze badanie stanowisk archeologicznych, rozwijał się od II wojny światowej, zwłaszcza od połowy XX w. ${ }^{14}$ Kształtowały go rady oświaty (kyouiku iinkai) samorządów lokalnych, zarówno na szczeblu prefektury, jak i gminy, pod nadzorem rządu krajowego. Komisje oświatowe odpowiadaja nie tylko za prowadzenie prac ratowniczych, ale także za ochronę i renowację stanowisk archeologicznych w każdej prefekturze

11 T. Watanabe, Maizou Bunkazai Kankei Toukei Sbiryou No Kaisetsu To Bunseki: Heisei 19 Nendo Ban (Statistical data on buried cultural properties in 2007: Commentary and Analysis), Gekkan Bunkaza, Tokyo 2008, s. 39.

12 K. Nakamura, Bunkazaibogoseido Gaisetsu (Outline of the system for the protection of cultural properties), Tokyo 1999, s. 13-19.

13 Cultural Properties Department, Agency for Cultural Affairs, Japan, Cultural Properties for Future Generations, Outline of the Cultural Administration of Japan, s. 3, https://www.bunka.go.jp/tokei_hakusho_shuppan/shuppanbutsu/bunkazai_pamphlet/pdf/r1393015_02.pdf (dostęp: 15.11.2021).

14 Agency for Cultural Affairs, Bunkazaihogohou Gojyunenshi (Fifty years of history of the Law for the Protection of Cultural Properties), Tokyo 2001, s. 263. 
lub gminie oraz za rozpowszechnianie i publikację informacji uzyskanych z badań archeologicznych w celach edukacyjnych. W ten sposób przyczyniły się do ustanowienia kompleksowego systemu AHM w Japonii ${ }^{15}$. Ten funkcjonujący od lat 60. $\mathrm{XX}$ w. system stoi dziś przed nowym wyzwaniem, jakim jest rosnąca presja na prywatyzację wykopów ratunkowych ${ }^{16}$.

Podstawą interwencji archeologicznej w Japonii jest ustawa o ochronie dóbr kultury, zainaugurowana w $1950 \mathrm{r}$. i regularnie aktualizowana. Zasoby archeologiczne pod ziemią są określone jako „zakopane/podziemne dobra kultury (Maizou Bunkazai)". Od tego czasu wszystkie wykopaliska muszą być zgłaszane do właściwego departamentu rządowego, tradycyjnie do Rady Edukacji. Większość archeologicznych badań terenowych przybiera formę wykopalisk ratowniczych (CRM) podejmowanych przed budowa, zamiast projektów badawczych. Uniwersytety przeprowadzaja głównie wykopaliska badawcze do celów naukowych. Naukowcy są zobowiązani do uzyskania od władz lokalnych pozwolenia na wykopaliska. Zgodnie z zasada, że lepiej jest zachować „zakopane dobra kultury”, niż dopuścić do ich zniszczenia, inicjator budowy musi zapłacić za wykopaliska archeologiczne przed zniszczeniem stanowiska ${ }^{17}$.

W Japonii tradycyjnie przyjmuje się, że koszt badań archeologicznych przed budowa prywatnych domów ponosi państwo (w przeciwieństwie do prawa polskiego, zgodnie z którym te koszty ponosi inwestor). W przypadku prac budowlanych prowadzonych w celach komercyjnych koszty ratowniczych wykopalisk pokrywa „zanieczyszczający", czyli deweloper (podmiot publiczny lub prywatny). Koszty te obejmują wydatki na wykopaliska, obróbkę znalezisk i publikację raportu z wykopalisk.

Ustawa o ochronie dóbr kultury nie określa jasno zasady „zanieczyszczający płaci”18. W \93-2 wskazano, że gdy istnieje „szczególna potrzeba” ochrony „zakopanych dóbr kultury" (maizo bunkazal) ${ }^{19}$, które pod wpływem prac rozwojowych są zagrożone, komisarz Agencji ds. Kultury może wskazać „niezbędne środki, jakie należy podjąć". Powszechnie przyjmuje się, że te środki obejmują wezwanie dewelopera do pokrycia kosztów prac ratowniczych. Jednak deweloper nie ma obowiązku pokrycia kosztów, ponieważ wspomniane środki stanowia jedynie zarządzenie administracyjne. Ta kwestia, wielokrotnie podnoszona przez ustawodawcę, jest jednym z głównych problemów ustawy o ochronie dóbr kultury.

15 M. Tanaka, Japan [w:] Approaches to the Archaeological Heritage: A Comparative Study of World Cultural Resource Management Systems, ed. H. Cleere, Cambridge 1984, s. 84.

16 T. Inada, Archaeological Heritage Management and Administrative Reform, „Koukogaku Kenkyuu (Quarterly of Archaeological Studies)" 2006, vol. 53, no. 2, s. 73.

17 K. Okamura, Japan: Cultural Heritage Management Education [w:] Encyclopedia of Global Archaeology, ed. C. Smith, Osaka 2014, s. 4162.

18 M. Tanaka, Japan..., s. 84.

19 Termin powszechnie używany w Japonii na określenie „podziemnych pozostałości archeologicznych". 
Zasada „zanieczyszczający płaci” została po raz pierwszy zastosowana w 1958 r., kiedy prace ratownicze wymagane przed budową drogi ekspresowej Meishin zostaky sfinansowane przez dewelopera Japan Highway Public Corporation ${ }^{20}$. Ta sama zasada została powtórzona w protokołach, które Agencja ds. Kultury wymieniła $z$ innymi organami odpowiedzialnymi za roboty publiczne, takimi jak Japan Housing Corporation i Japan Rail-way Construction Public Corporation ${ }^{21}$. Co więcej, zaczęła być stosowana tradycyjnie również wobec prywatnych firm deweloperskich. W latach 60. japoński rząd wdrożył Wszechstronny Krajowy Plan Rozwoju (Zenkoku Songou Kaihatsu Seichou Keikaku). Skutkowało to znacznym rozwojem infrastruktury, w tym sieci autostrad, terenów przemysłowych, nowych miast przemysłowych, kolei dużych prędkości i lotnisk. To zaś stworzyło pilną potrzebę podjęcia działań ratowniczych na terenie całego kraju ${ }^{22}$.

\section{Stanowiska archeologiczne i kulturowe}

Obecnie społeczeństwo japońskie wykazuje duże zainteresowanie archeologia w swoim kraju ${ }^{23}$. Na kanwie tego zainteresowania powstały różne programy informacyjne na temat archeologii japońskiej jako nauki o przodkach „narodu japońskiego". Archeolodzy w trakcie publicznych spotkań poświęconych interpretacji stanowisk Jomon oraz innych miejsc archeologicznych wielokrotnie powtarzali, że głównym celem japońskiej archeologii jest rekonstrukcja życia ich własnych przodków. Jest to całkowicie odmienne podejście od typowego dla obu Ameryk postrzegania ,archeologii jako antropologii”, które pierwotnie rozwinęło się jako nauka o przeszłości innych (others).

Wykopy ratownicze i późniejsze przygotowanie raportu z lokalizacji, finansowane z podatków z różnych szczebli rządowych, byłyby niemożliwe bez silnego wsparcia ze strony społeczeństwa. Dzięki ogromnemu wsparciu i zaangażowaniu lokalnego społeczeństwa udało się zachować niektóre stanowiska archeologiczne Jomon, które początkowo odkrywano jako wykopy ratunkowe prowadzone przed realizacją projektów ${ }^{24}$. Społeczne zainteresowanie badaniami archeologicznymi było

\footnotetext{
20 Agency of Cultural Affairs, Bunkazaihogohou Gojyunenshi..., s. 268-269.

${ }^{21}$ K. Tsuboi, Issues in Japanese Archaeology [w:] Acta Asiatica 63, eds. K. Tsuboi, Toho Gakkai, Tokyo 1992, s. 3.

22 K. Okamura, A. Matsuda, Archeological Heritage Management in Japan [in:] Cultural Heritage Management, 2010, s. 110-111, https://www.researchgate.net/publication/292866117_Archaeological_Heritage_Management_in_Japan (dostęp: 15.11.2021).

${ }^{23}$ J. Habu, C. Fawcett, Jomon archaeology and the representation of Japanese origins, „Antiquity” 1999, vol. 73 , issue 281 , s. 587-593.

24 Y. Okada, J. Habu, Public presentation and archaeological research: A case study from the Jomon Period Sannai Maruyama site, Paper presented at the 1995 Chacmool Conference, Calgary 1995.
} 
podsycane przez doniesienia medialne od lat 70., kiedy to zaczęły pojawiać się japońskie gazety i programy telewizyjne donoszące w sensacyjny sposób o odkryciach archeologicznych.

Związek między japońską archeologią a pochodzeniem etnicznym i tożsamością narodową można wyjaśnić za pomoca japońskiego terminu nibonjinron. Nibonjinron to dyskurs o japońskiej tożsamości, który koncentruje się na opisie i zrozumieniu wyjątkowości cech Japonii, Japończyków i samej kultury japońskiej. Japońskie i zagraniczne elity intelektualne od 1970 r. formułowany wiele twierdzeń, które trafiły do popularnonaukowego obiegu za pomocą środków masowego przekazu i liderów biznesu chętnych do umiędzynarodowienia japońskiej siły roboczej ${ }^{25}$.

Od 1945 r. badania archeologiczne stały się ważnym sposobem kształtowania japońskiej tożsamości narodowej ${ }^{26}$. Specjaliści i niespecjaliści informowali autorów dyskursu nihonjinron o znaczeniu wydobytych materiałów dla odtworzenia przez naukowców pochodzenia Japończyków i historii rozwoju państwa japońskiego. Ta powojenna archeologia była nieoceniona w kształtowaniu dumy z osiagnięć ludzi, którzy żyli w starożytności na archipelagu japońskim. Zachęciło to japońska opinię publiczną do rozważenia istnienia ważnych wpływów ludów i kultury Azji kontynentalnej na rozwój Japonii. Jednocześnie wykorzystano wyniki badań archeologicznych, aby wzmocnić poczucie homogeniczności i wyjątkowości etnicznej Japonii. Dzięki takiemu rozumieniu archeologii w latach 70. i 80. wyznaczono Asuka Village, obszar w prefekturze Nara, na którym przeprowadzono dużą liczbę badań archeologicznych, a miejsca na nim odkryte datowano na okres od połowy VI do początku VIII w. Na tym obszarze powstało archeologiczne centrum turystyczne, które dzięki specjalnym przepisom pozostało obszarem nienaruszonym i nieprzekształconym ${ }^{27}$.

\section{Krag kamienny Omori Katsuyama}

Wydaje się, że wszystkie ludy neolityczne (lub trochę późniejsze) miały swoje kręgi, tworzone $z$ różnym rozmachem ${ }^{28}$. Miejsca te miały znaczenie spirytualne (religijne) lub zwyczajnie użytkowe (pełniły funkcję cmentarzy, funkcję kalendarza, były miejscem spotkań). W Japonii jednak kamienne kregi są rzadko spotykane. Japoński kamienny krąg Omori Katsuyama znajduje się na czubku 145-metrowego wzgórza w kształcie języka, po północno-wschodniej stronie podnóża góry Iwaki

25 H. Befu, Civilisation and culture: Japan in search of identity [w: Japanese civilisation and the modern world: Life and society, eds. T. Umesao, H. Befu, J. Kreiner, Senri Ethnological series 16, Osaka 1984.

26 C. Fawcett, Archaeology and Japanese identity [w:] Multicultural Japan, eds. D. Denoon et al., Cambridge 1996, s. 74 .

27 Ibidem, s. 62.

28 Jednym z najbardziej popularnych kamiennych kręgów jest stanowisko archeologiczne Stonehenge w Anglii. 
w zachodniej prefekturze Aomori. Krag jest datowany na pierwsza połowę ostatniego okresu Jomon (ok. 1000 r. p.n.e) ${ }^{29}$. Kamienny krag Omori Katsuyama ma eliptyczny kształt o średnicy 48,5 m w dłuższej osi i 39,1 m w krótszej osi, został zbudowany przez przygotowanie okrąłego, przypominającego wzgórze nasypu na płaskich połączonych kamieniach (dokładnie 77) wzdłuż krawędzi wału. Układ połączonych kamieni i inne wyjątkowe aspekty kamiennego kręgu sprawiają, że jest on bardzo ważny jako materialny dowód powstawania wielkich zabytków w okresie Jomon. Krag znajduje się w miejscu, w którym nad szczytem góry Iwaki w czasie przesilenia zimowego słońce zachodzi ${ }^{30}$.

Megality takie jak ten występuja na całym świecie, a ich tworzenie jest cechą wspólną całej ludzkości, pomimo różnic geograficznych i kulturowych. Na terenach Europy megality powstawały od ok. V tysiąclecia p.n.e aż do II tysiąclecia p.n.e. Budowle te zazwyczaj były związane z kultem przodków, dla których budowano okazałe grobowce oraz z kultem słońca, czego rezultatem było ustawienie budowli w taki sposób, by w określone dni roku widać było gwiazdy lub słońce od strony wschodniej lub zachodniej ${ }^{31}$. Megality mogły być także otwartymi świątyniami i obserwatoriami astronomicznymi.

2. Hiraizumi - świątynie, ogrody i stanowiska archeologiczne reprezentujące czystą ziemię buddyjską

W XII w. Hiraizumi było politycznym i administracyjnym centrum w północnej części japońskiej wyspy Honshû, będącej wówczas pograniczem między terytoriami rządzonymi przez centralny rząd Japonii a regionami położonymi dalej na północ. Ich ożywiony handel z tymi regionami stanowił podstawę gospodarki. Klan ôshû Fujiwara żyjący w tamtym rejonie wywodził się z tradycji samurajów, ale dzięki sile ogromnego bogactwa zgromadzonego przez cztery pokolenia rodzina ta nie polegała wyłącznie na swojej potędze militarnej. Zbudowali oni Hiraizumi w celu stworzenia „Czystej Krainy - buddyjskiej koncepcji idealnego świata”. Hiraizumi stanowiło wzorzec dla podobnych koncepcji związanych z kultywowaniem religii.

29 Omori Katsuyama Stone Circle, Jamon Prehistoric Sites in Northern Japan, https://jomon-japan. jp/en/jomon-sites/omori-katsuyama/ (dostęp: 8.01.2021). W archeologii japońskiej wyróżniamy wiele okresów (Yayoi, Jomon itp.), które są również nazwami używanymi do określenia odpowiednich kultur (w polskiej czy europejskiej archeologii nie stosuje się podobnego systemu). Każdy z tych okresów jest podzielony na 3 do 6 podokresów ('środkowy Yayoi, najwcześniejszy Jomon itp.). W okresie Jomon podokresy są dalej dzielone (nieoficjalnie) na wiele krótszych faz: początek, środek, środek środka, koniec, koniec końca. Te krótsze fazy rozróżnia się z grubsza na podstawie rodzaju wytwarzanej w danym czasie ceramiki, która w Japonii, w zależności od okresu, jest łatwo rozróżnialna. Okres Jomon trwał od 14 tys. lat p.n.e. do 1000 r. p.n.e. Okres końcowy Jōmon jest szacowany na lata 3520-2470 p.n.e.

30 Ibidem.

31 M. Brennan, The stars and the stones, London 1983, s. 7. 
Cztery ogrody Pure Land w Hiraizumi, w tym trzy skupione na świętej górze Kinkeisan, są przykładem połączenia ideałów buddyjskiej Czystej Krainy i przekonań rdzennych Japończyków, które odnoszą się do relacji między ogrodami, woda i otaczającym krajobrazem. Dwa ogrody zostały zrekonstruowane, wiele szczegółów odzyskano dzięki wykopaliskom, a dwa wciąż pozostają zakopane. W XI i XII w. miasto Hiraizumi było politycznym i administracyjnym centrum północnej części Japonii i rywalizowało z Kioto pod względem politycznym i handlowym. Cztery ogrody zostały zbudowane jako symboliczne przejawy buddyjskiej Czystej Krainy na tej ziemi. Wizja raju została zmaterializowana poprzez staranne rozmieszczenie świątyń w stosunku do stawów, drzew i szczytów Mount Kinkeisan. Mocno złocona świątynia Chûson-ji (jedyna zachowana z XII w.) odzwierciedlała wielkie bogactwa ówcześnie rządzącego klanu.

Znaczna część obszaru miasta została zniszczona w 1189 r., kiedy utraciło ono status polityczny i administracyjny. Spektakularny wzrost i rzucające się w oczy bogactwo Hiraizumi oraz jego równie szybki i dramatyczny upadek stały się źródłem inspiracji dla wielu poetów. W 1689 r. Matsuo Basho napisał haiku: „Trzy pokolenia chwały zniknęły w przestrzeni snu..."32. Cztery kompleksy świątynne tego niegdyś wielkiego centrum, wraz z ogrodami i wspomniana, zachowaną do dzisiaj dwunastowieczną świątynia, a także ich związek ze świętą górą Kinkeisan tworzą wyjątkowe stanowisko, odzwierciedlające bogactwo i siłę Hiraizumi oraz swoistą koncepcję planowania i projektowania ogrodów, która wpłynęła na kształt ogrodów i świątyń w innych miastach Japonii ${ }^{33}$.

\section{Ise Grand Shrine - światynia ciagle odbudowywana}

Ise Grand Shrine znajduje się w prefekturze Mie, około godziny drogi od Nagoi i 2 godziny od Osaki. Dla Japończyków jest to najświętsze miejsce w całym kraju. Jego historia sięga III w. Świątynia ta jest domem shinto, narodowej religii Japonii, a tym samym jest najważniejszą świątynią shinto w kraju i jedną z najpopularniejszych. Co roku przyciąga $6 \mathrm{mln}$ pielgrzymów i turystów z całego świata. Według wierzeń Japończyków w Ise Grand Shrine mieszka Amaterasu (bogini słońca), która jest najwyższym bóstwem w Japonii. Według legendy jej potomkami są członkowie rodziny cesarskiej. Popularnie to miejsce jest nazywane Ise Jingu.

W Japonii istnieja trzy podstawowe poziomy świątyni Shinto: jinja (神社), taisha (大社) i jingu (神宮). Jingu to najwyższa klasyfikacja miejsc kultu, a te muszą mieć historyczne powiązania z członkiem rodziny cesarskiej lub powstać dla uczczenia jego pamięci.

32 M. Basho, Summer grass, https://matsuobashohaiku.home.blog/2019/04/01/summer-grass$\% \mathrm{E} 5 \% \mathrm{~A} 4 \% 8 \mathrm{~F} \% \mathrm{E} 8 \% 8 \mathrm{D} \% 89$-natsuka/ (dostep: 9.01.2021).

33 UNESCO, Hiraizumi - Temples, Garden and Archaeological Sites Representing the Buddhist Pure Land, https://whc.unesco.org/en/list/1277/ (dostęp: 10.01.2021). 
Sama historia Ise Grand Shrine sięga półmitologicznej epoki Japonii, a jej powstanie zostało opisane w Nihon Shoki (日本書紀), znanej również jako Kroniki Japonii, drugiej najstarszej księdze klasycznej historii Japonii. Opowieść o duchowym dziedzictwie sanktuarium mówi: „moce, o których zdecydowano, Amaterasu potrzebowała stałego miejsca kultu"34. Panujący wówczas cesarz, XI cesarz Suinin, nakazał swojej księżniczce Yamatohime-no-mikoto znaleźć odpowiednie miejsce. Księżniczka wędrowała po kraju przez prawie 20 lat, zanim sama bogini słońca podpowiedziała jej, że piękny kraj Iseia będzie odpowiednim domem. Świątynia ta stała się znana jako świątynia wewnętrzna (Naiku), a ok. 500 lat później dodano świątynię zewnętrzną (Geku). Zarówno kapliczka zewnętrzna, jak i wewnętrzna tworzą Wielką Świątynię Ise.

Dzisiejsza świątynia nie jest oryginalną świątynią zbudowaną w III w. Jest ona bowiem regularnie odnawiana. Ceremonia odnowienia, która odbywa się co 20 lat, nazywana jest Shikinen Sengu lub Sengushiki i jest unikalna dla Iseia. Budynki są całkowicie przenoszone na jedną z dwóch „działek” (na prawo lub lewo) o dokładnie tych samych wymiarach: na jednej działce stawiane są budynki świattyni, natomiast na drugiej pozostaje pole kamieni z małą drewnianą konstrukcją z binoki (kijem), na której miejscu za 20 lat zostanie wzniesiony następny święty „,filar serca”. Kiedy stare sanktuarium jest demontowane, pochodzace z demontażu materiały są przekazywane innym jinja w całym kraju, przy czym święte lustro, które jest symbolem Amaterasu-Omikami, zostaje przeniesione do nowego sanktuarium. Shikinen Sengu obejmuje 32 rytuały i ceremonie, z których pierwszym jest wycinanie 14 tys. binoki (z cyprysu japońskiego) oraz cedrów białych do następnej przebudowy. Całość procesu odnowienia trwa ok. 8 lat ${ }^{35}$. Odbudową zajmuje się mała grupa rzemieślników i kapłanów-cieśli zobowiązana do przerobienia 65 konstrukcji i ok. 16 tys. artefaktów ${ }^{36}$.

\section{Podsumowanie}

Kultura japońska jest niezwykle bogata, szybko ewoluowała w ostatnim stuleciu. Postęp technologiczny, przyjęcie przez rząd praw demokratycznych i wzrost liczby ludności w kraju wprowadziły nowy styl życia jego mieszkańców. Te nowoczesne osiagnięcia często mogą wydawać się niezgodne z tradycyjną kulturą japońską. Niemniej jednak wiele tradycyjnych wartości Japonii nadal stanowi podstawę kultury.

34 T. Akima, The Origins of the Grand Shrine of Ise and the Cult of the Sun Goddess Amaterasu Omikami, ,Japan Review” 1993, no. 4, s. 141-198, https://www.jstor.org/stable/25790929 (dostęp: 9.01.2021).

35 M. Louw, The Craft of Memory and Forgetting, "The South African Journal of Art History” 2017, vol. 32, no. 2, s. 10.

36 D. Young, M. Young, The Art of Japanese Architecture, North Clarendon 2007, s. 34. 
Japończycy nie zawsze szukali poszukiwania wyraźnej tożsamości, rozumianej jako świadomość historyczna. W historii narodu japońskiego jest jeden niechlubny okres, kiedy to zakazywano starych zwyczajów i nakazywano przyjmowanie nowych - europejskich. Nigdy jednak Japończycy nie niszczyli celowo zabytków archeologicznych. Badania archeologiczne sa intensywnie prowadzone od niedawna. Przepisy prawa nie reguluja ich wszystkich koniecznych aspektów. Do uregulowania pozostaje kwestia stanowisk podwodnych. Prawdopodobnie większość nieodkrytych stanowisk archeologicznych w Japonii znajduje się pod woda. Chociaż obecnie obowiazzujące prawo nie wspomina o artefaktach znalezionych pod woda, na co wskazuje chociażby całkowity brak wyrażenia ,pod woda, podwodny” w kodeksie czy ustawie, nie powinniśmy wątpić, że zatopione tereny są chronione. Miejsca podwodne mogą być w Japonii chronione, jeśli zostaną zarejestrowane. Problem polega jedynie na tym, jak wpisać takie stanowisko na listę ${ }^{37}$. Najlepszym sposobem ochrony obiektów jest zdefiniowanie ich jako dobra kultury. W takim przypadku obiekt uzyskuje taką samą ochronę, niezależnie czy jest to stanowisko lądowe, czy podwodne.

Chociaż kluczowym celem archeologii w Japonii nadal pozostaje budowanie tożsamości narodowej w odniesieniu do przeszłości, zauważalne jest zróżnicowanie celów badawczych i metodologii stosowanej przez obecne pokolenie praktykujących archeologów. Liczne projekty budowlane zagrażające pozostałościom archeologicznym wywołały oburzenie opinii publicznej z powodu możliwości utraty dziedzictwa kultury, co przełożyło się na zmianę przepisów i regulacji oraz ustanowienie rozbudowanego, sponsorowanego przez rząd systemu archeologii ratunkowej, który zatrudnia tysiące zawodowych archeologów. Spowolnienie gospodarcze i tendencje do prywatyzacji instytucji $\mathrm{w}$ ostatnich dziesięcioleciach stwarzają nowe wyzwania dla społeczności archeologicznej, aby opracować strategię utrzymania jakości prac archeologicznych.

W Japonii dziedzictwo kultury stało się lepiej znane po części ze względu na wzrost zainteresowania miejscami światowego dziedzictwa wśród entuzjastów podróży zainicjowanych przez popularny program telewizyjny tuż po podpisaniu przez rząd japoński w 1992 r. Konwencji w sprawie ochrony światowego dziedzictwa kulturalnego i naturalnego, przyjętej w Paryżu dnia 16 listopada 1972 r. (Dz. U. z 1976 r. Nr 32, poz. 190). Termin dziedzictwo kultury nie jest używany w odniesieniu do krajowych miejsc „dziedzictwa” i nie zają jeszcze miejsca tradycyjnego terminu „dobra kultury”.

37 R.J. Sasaki, S. Imazu et al., The history, status and future of Underwater Cultural Heritage Management in Japan, The MUA Collection, s. 7, http://www.themua.org/collections/items/show/1630 (dostęp: 18.11.2021). 


\section{Literatura}

Agency for Cultural Affairs, Bunkazaibogohou Gojyunenshi (Fifty years of history of the Law for the Protection of Cultural Properties), Tokyo 2001.

Akima T., The Origins of the Grand Shrine of Ise and the Cult of the Sun Goddess Amaterasu Omikami, „Japan Review" 1993, no. 4.

Basho M., Summer grass, https://matsuobashohaiku.home.blog/2019/04/01/summer-grass-\%E5 $\% \mathrm{~A} 4 \% 8 \mathrm{~F} \% \mathrm{E} 8 \% 8 \mathrm{D} \% 89$-natsuka/ (dostęp: 15.11.2021).

Befu H., Civilisation and culture: Japan in search of identity [w:] Japanese civilisation and the modern world: Life and society, eds. T. Umesao, H. Befu, J. Kreiner, Senri Ethnological series 16, Osaka 1984.

Bestor T.C., Countries and their cultures, https://www.everyculture.com/Ja-Ma/Japan.html (dostęp: 15.11.2021).

Bowles G., Japanese People, Origin of, KEJ 1983, vol. 4.

Brennan M., The stars and the stones, London 1983.

Farris W., Population, Disease, and Land in Early Japan, 645-900, Cambridge, MA 1985.

Fawcett C., Archaeology and Japanese identity [w:] Multicultural Japan, eds. D. Denoon, M. Hudson, G. McCormack, T. Morris-Suzuki, Cambridge 1996.

Grapard A.G., Nature and Culture in Japan, „Kyoto Journal”, 30.11.2012, https://kyotojournal. org/culture-arts/nature-and-culture-in-japan/ (dostęp: 19.02.2021).

Habu J., Fawcett C., Jomon archaeology and the representation of Japanese origins, „Antiquity” 1999, vol. 73 , issue 281 .

Inada T., Archaeological Heritage Management and Administrative Reform, „Koukogaku Kenkyuu (Quarterly of Archaeological Studies)" 2006, vol. 53, no. 2.

Japan - Country Profile, Facts, News and Original Articles, Global Sherpa, http://globalsherpa.org/ japan/ (dostęp: 15.11.2021).

Katayama K., The Japanese as an Asia-Pacific Population [w:] Multicultural Japan: Paleolithic to Postmodern, eds. D. Denoon, M. Hudson, G. McCormack, T. Morris-Suzuki, New York 1996.

Keally C.T., Japanese Archeology, http://www.t-net.ne.jp/ keally/jpnarch.html (dostęp: 20.02.2021).

Louw M., The Craft of Memory and Forgetting, „The South African Journal of Art History” 2017, vol. 32 , no. 2 .

Nakamura K., Bunkazaibogoseido Gaisetsu (Outline of the system for the protection of cultural properties), Tokyo 1999.

Okada Y., Habu J., Public presentation and archaeological research: A case study from the Jomon Period Sannai Maruyama site, Paper presented at the 1995 Chacmool Conference, Calgary 1995.

Okamura K., Japan: Cultural Heritage Management Education [w:] Encyclopedia of Global Archaeology, ed. C. Smith, Osaka 2014.

Okamura K., Matsuda A., Archeological Heritage Management in Japan [in:] Cultural Heritage Management, 2010, https://www.researchgate.net/publication/292866117_Archaeological_Heritage_ Management_in_Japan (dostęp: 15.11.2021).

Okamura M., Babadan A., Pearson R., Ancient Japan, contribution to Pearson, New York 1992.

Omori Katsuyama Stone Circle, Jamon Prehistoric Sites in Northern Japan, https://jomon-japan.jp/ en/jomon-sites/omori-katsuyama/ (dostęp: 8.01.2021).

Pearson R., Ancient Japan, New York 1992.

Sasaki R.J., Imazu S. et al., The history, status and future of Underwater Cultural Heritage Management in Japan, The MUA Collection, http://www.themua.org/collections/items/show/1630 (dostęp: 18.11.2021). 
Tanaka M., Japan [w:] Approaches to the Archaeological Heritage: A Comparative Study of World Cultural Resource Management Systems, ed. H. Cleere, Cambridge 1984.

Tsuboi K., Issues in Japanese Archaeology [w:] Acta Asiatica 63, eds. K. Tsuboi, Toho Gakkai, Tokyo 1992.

UNESCO, Hiraizumi - Temples, Garden and Archaeological Sites Representing the Buddhist Pure Land, https://whc.unesco.org/en/list/1277/ (dostęp: 10.01.2021).

Watanabe T., Maizou Bunkazai Kankei Toukei Shiryou No Kaisetsu To Bunseki: Heisei 19 Nendo Ban (Statistical data on buried cultural properties in 2007: Commentary and Analysis), Gekkan Bunkaza, Tokyo 2008.

Young D., Young M., The Art of Japanese Architecture, North Clarendon 2007.

\section{SUMMARY}

\section{PROTECTION OF ARCHAEOLOGICAL SITES IN JAPANESE LAW}

In popular perception Japan is often associated with cherry blossoms, the samurai, the geishas, rice fields and delicious ramen soup. However, each of these elements is relatively new. The country's culture is rich and ancient, and the Japanese are very aware of their heritage and are eager to protect it. The Japanese government encourages universal public participation in supporting and appreciating artistic activities. The most important cultural goods are considered national treasures, which are particularly valuable to the world and to the Japanese nation. These can be works of art such as paintings, sculptures or architectural masterpieces, as well as other forms of artistic expression such as suiseki - art of artistic display of stones, chado - tea ceremony, ikebana - flower arrangement, and even the artists themselves. The purpose of this article is to outline the Japanese heritage law with respect to protection of archaeological sites; the long history of the island nation means the Japanese archaeologists have plenty of sites to work on. Since 1945, archaeological research has become an important way of constructing the Japanese national identity. While the key goal of archeology in Japan is still about building national identity in relation to the past, there is a noticeable diversity in research goals and methodology used by the current generation of practicing archaeologists. 